\title{
Developing an Information Management Strategy for e-Government in Saudi Arabia
}

\author{
Fatmah Almehmadi \\ College of Computer and Information Systems \\ Umm Al-Qura University (UQU), Makkah, Saudi Arabia
}

\begin{abstract}
Given the current Corona virus pandemic, the role of e-government in both developed and developing countries is becoming more important than ever. This study aims to assess the development of e-government in Saudi Arabia and to compare it with that of two world e-government leaders: USA and the Republic of Korea, during the period of 2003-2020. Data analysis consists of: 1) a comparative, cross-country, longitudinal analysis of the e-government development index (EGDI) relating to Saudi Arabia, the USA and the Republic of Korea; 2) a trend analysis of the online services, telecommunication infrastructure, and human capital indicators; and 3) a gap analysis to pinpoint the gap between Saudi Arabia and the USA, and the gaps between Saudi Arabia and the Republic of Korea. The results reveal a continuous rise in the rankings of Saudi Arabia's EGDI over the years. However, findings also indicate some areas that require more improvement. An information management strategy for the support of e-government in Saudi Arabia has been developed, describing the current e-government situation and setting high, medium, and low-level priorities that the country needs to consider in order to better its compliance with international e-government practices.
\end{abstract}

Keywords-e-Government; Information technology; Information management; Trend analysis; Saudi Arabia; the USA; the Republic of Korea

\section{INTRODUCTION}

Digital transformation and, in particular, the role of egovernment is becoming more prominent worldwide, given the current Corona virus (COVID-19) pandemic, which requires people to adapt their previous daily working styles so as to work primarily online. Previous research suggests that egovernment incorporates many elements such as eadministration, e-services, and e-society. However, at its core, e-government focuses on delivering governmental services to people via the adoption and use of information and communication technologies (ICT). While e-government; as a concept, emerged in the United States in 1995, as a new administrative project for the state of Florida's central mail, its acknowledged, widespread use began in 2001 [1]. Since then, there has been a growing interest in exploring the topic. As a term, e-government has been defined a number of ways in previous literature; however, it is often referred to as the use of information and communication technologies (ICTs) to enable the provision and delivery of government services for citizens, businesses, and organizations. For example, in 2001, the World Bank defined e-government as "the government owned or operated systems of information and communication technologies that transform relations with citizens, the private sector and/or other government agencies" [2] (p. 4). eGovernment is also conceptualized in [3] as governments' use of ICTs together with organizational change to enhance their structures and operations.

The significance of e-government is well recognized by both developed and developing countries. However, previous reports that have explored e-government on a global scale, such as the series of reports conducted by the United Nations (UN), point to a gap between developed and developing countries in terms of the adoption and implementation of egovernment, and suggest that this gap needs to be addressed [4,5]. Saudi Arabia is one of the developing countries that needs to learn from more developed countries so as, to ensure compliance with the best global e-government practices.

In Saudi Arabia, e-government is regarded as beneficial for a variety of different purposes, most notably those relating to the management of organizational processes and religious events, such as pilgrimages or the Hajj. In fact, there have been many e-government initiatives in the country in recent years, as it is in a process of transition to e-government. Indeed, reports of the National Transformation Program 2020 and of the Saudi Vision 2030 highlight the importance of further development of e-government initiatives. These reports also indicate the Saudi government's commitment to the adoption and use of ICT to fully transition to e-government. However, research investigating the evolution of egovernment in Saudi Arabia over time is still limited, especially when compared to that conducted in other developed countries. For example, a study of e-government [1] (p. 4) calls for further research "to evaluate the accomplishment of e-government projects in the Arab World." This paper, therefore, aims to investigate and assess the development of e-government in Saudi Arabia.

The research questions that the current study aims to address are: 1) How has e-government in Saudi Arabia evolved during the period of 2003 to 2020?, 2) How does the development of e-government in Saudi Arabia differ from the development of e-government in the USA and in the Republic of Korea (RoK)? These two countries have been chosen because, according to UN e-government reports, they have been ranked first globally more than one occasion; the USA was ranked first in 2003, 2004, and 2005, while the RoK was ranked first in 2010, 2012, 2014.

This research aims to evaluate the development of egovernment in Saudi Arabia during the period 2003-2020, and to compare it with the development of e-government in the

fmmehmadi@uqu.edu.sa. 
USA and the RoK, given that these two countries are considered to be among e-government world leaders. The objectives of the study are as follows:

- To track the evolution of e-government in Saudi Arabia during the period 2003 to 2020 .

- To compare the level of progress of e-government in Saudi Arabia with that of world leading countries, namely the USA and the RoK.

- To identify the similarities and differences that relate to e-government development between Saudi Arabia, the USA, and the Rok.

- To identify the most important aspects that need to be considered to enhance e-government in Saudi Arabia.

- To develop an information management strategy prioritizing the key aspects of e-government that need to be addressed to further improve e-government in Saudi Arabia.

The present study adds to existing knowledge in the field. Firstly, it differs from most prior studies, which, while revealing valuable insights about e-government, often focused on case studies of a single country. In this study, however, the approach is different, in that it offers a cross-country comparison by evaluating the level of e-government progress in Saudi Arabia alongside that in the USA and the RoK. Secondly, it is hoped that the findings of this study and the lessons that can be learned from e-government development in the USA and the RoK can be used to reposition Saudi Arabia on its roadmap to improve its EGDI ranking in the upcoming UN review reports. As one author [6] (p. 7) notes that for successful implementation of e-governments, there is a need to learn from the experience of other countries especially those which were considered successful or highly ranked. Thirdly, the findings of this study can be used by policy and decision makers in Saudi Arabia to consider specific factors or areas that may help to further develop e-government in the country.

The subsequent sections provide a review of the relevant literature, an explanation of the research methodology, a detailed presentation of the results, a discussion of the key findings, and the conclusions of the study.

\section{REVIEW OF LITERATURE}

\section{A. Benefits of e-Government}

The adoption and implementation of e-government can bring various benefits for citizens, businesses, and public sector organizations $[1,2,6]$. In terms of benefits for citizens, it can lead to the delivery of services in a way that is not only convenient, but also cost-effective. Another benefit is reducing the time citizens need to spend applying for and following-up on government services. In addition, egovernment can benefit by providing online access to government services via different devices, such as computers and smart phones. As discussed in [7,8], a further advantage is transparency, since citizens can easily monitor their applications for government services and the different procedures required to process these applications.
E-government can also be beneficial for businesses because it is likely to enhance the quality of services and facilities that are provided by the government to businesses and private sector companies. This, in turn, can lead to the provision and delivery of convenient, cost-effective, and timesaving services to these businesses [9]. In addition, according to [10], e-government systems that are used by private sector entities can be beneficial in terms of the simplification and improvement of supply chain and marketing process management.

There are also many benefits of e-government when it comes to public organizations, including the efficient and effective management of the data and information created, processed, and delivered by these organizations. Indeed, the adoption and implementation of e-government can offer an opportunity to develop a knowledge base system that can be collaboratively used for better services provision. In this regard, e-government can also further improve the performance of the public sector, as it supports information sharing among the sector's different organizations [6].

\section{B. Barriers to e-government}

There are various challenges that can hinder the successful adoption and implementation of e-government. These, according to [6], can also delay the progress made towards realizing its full potential. Although such obstacles vary from one country to another, there are common barriers that most countries encounter [11]. One of the key challenges to egovernment, especially in developing countries, is inadequate ICT infrastructure [12]. E-government initiatives in developing countries often face technical obstacles, such as a lack of compatible technical infrastructure and of shared standards among different government departments [6]. This, in turn, can lead to partial or complete failure of e-government initiatives. Indeed, one study [13] finds, in developing countries, this technical factor contributes to the complete failure of $35 \%$ of e-government projects, and the partial failure of $50 \%$ of e-government projects. Additionally, three recent studies [14] investigating barriers to e-government in the Arab world, come to the conclusion that inadequate ICT infrastructure is the technical factor most likely to impede the successful implementation of e-government in Arab countries.

Another obstacle to e-government implementation is related to policy and regulation issues. The transition to egovernment systems, especially in developing countries, often only focuses on technical issues, like sustaining suitable hardware and software. However, this transitional process should also consider organizational issues such as, developing a range of adequate rules, policies, and guidelines to deal with such matters as archiving, e-signatures, and data protection through e-government systems [6]. One of the challenges that faces developing countries when they transit to e-government systems is the lack of adequate rules to regulate e-government activities or processes. This can delay or lead to the potential failure of the implementation of e-government. E-government websites often ask for personal data, and people maybe be reluctant to make use of these systems if they feel that their privacy is at risk or that information security is not sufficiently guaranteed $[11,15]$. 
A further challenge that can negatively affect the adoption and implementation of e-government is the lack of qualified staff and training. Two e-government studies have stated that "government should train its employees and citizens in basic skills of dealing with the computer and Internet in order to let them participate in e-government development applications" [6] (p. 40). Previous studies indicate that a lack of ICT skills among e-government personnel can be a common problem, and is often reported as a significant challenge, particularly fort developing countries [16]. This is frequently coupled with inadequate staff training [14], which may further hinder the proper implementation of e-government, given that it requires qualified employees with the technical skills vital for egovernment logistics, such as the installation of ICT systems and the management of online processes and applications [6].

\section{C. e-Government in Saudi Arabia}

Saudi Arabia is located in South-West Asia and is one of the largest Arab countries, covering an area of around $2,000,000$ square kilometers. The country has a population of around 33,414,660 people [17], and an approximate population growth of $2.52 \%$ every year [18].

The kingdom of Saudi Arabia (KSA) recognizes the significance of the adoption and use of e-government. A Royal Decree directive to the Ministry of Communications and Information Technology (M.C\&IT) was issued in 2003 to develop an e-government transitional plan [19]. In 2005, the M.C\&IT, in collaboration with the Ministry of Finance and the Commission of Communications and Information Technology (C.C\&IT) developed the e-government national program, called Yesser [20]. The two main objectives of this program are: 1) to raise productivity and efficiency of public sector organizations, and 2) to provide easy-to-use services for both citizens and businesses. According to [19-21], the Yesser program has put forward several initiatives to address these objectives. These initiatives are related to human capital, eservices provision, national databases, e-procurement systems, infrastructure, and institutional frameworks including rules and regulations.

Nonetheless, the transition to an e-government system in a developing country like Saudi Arabia is often a complex process with various challenges along the way. Indeed, egovernment in developing countries can be fraught with difficulties arising from barriers such as a lack of adequate ICT infrastructure, and bureaucratic inefficiency [6]. A study by [16] indicates that Arabian Gulf countries, including Saudi Arabia often have incomplete ICT infrastructure, owing to the absence of local IT industries, which, when compared to foreign IT industries, may be better able to accommodate ICT infrastructure requirements. Another study by [22] highlights the inadequacy of ICT infrastructure and websites for people with special needs such as, blind citizens, and indicates that this problem can hinder the adoption and implementation of egovernment. It concludes that there is a need to review accessibility policies in all Arabian Gulf countries including Saudi Arabia so as to "accelerate the transition to accessible egovernment websites" which should also "serve all kinds of citizens, including [the] disabled" [22] (p. 6). This is in line with the findings of another study [23], which argues that a significant effort should be made to ensure that websites in Saudi Arabia become more accessible to all citizens.

An additional challenge is the lack of staff qualified to operate and manage e-government. One study [6] argues that this challenge, if not properly addressed through adequate training, can hinder the implementation of e-government initiatives. Another study [16] indicates that a lack of qualified staff can be regarded as a problem in Saudi Arabia and other developing countries. Human resources and qualified personnel are considered essential to realize success in terms of e-government, since it requires different human capacities, whether technical or managerial $[6,14]$. To address the challenge relating to human resources in developing countries, including Saudi Arabia, two scholars [6] suggest developing a knowledge management strategy, focusing on the provision of adequate training, accessible to all e-government staff.

Policy issues represent another obstacle. One study [22] contends that it is essential for different government agencies to operate with and adhere to the same set of rules. However, this is often not the case in developing countries, including Saudi Arabia, where "many government agencies have their own regulatory environment and strategic priorities" [16,24] (p. 3). Two studies [6] [14] also reveal similar results, and suggest developing a range of policies that address different egovernment activities such as archiving, signing, and data transmission and protection.

This study argues that learning lessons from world-leading countries in terms of e-government implementation is an essential step that developing countries like Saudi Arabia should consider. A good starting point from which to evaluate the evolution of e-government in Saudi Arabia and to compare it to that of other developed countries is the series of egovernment reports conducted by the UN since 2003 . The next section provides an overview of these reports.

\section{United Nations' e-Government Survey Reports}

The UN, which is a leading global organization, recognizes the significance of e-government and the range of different benefits it can bring to citizens, businesses, and organizations. Indeed, through its series of e-government reports starting in 2003, the UN encourages countries all around the world to adopt and implement e-government. These reports are based on the collaborative work of the United Nations Department of Economic and Social Affairs (DESA), and the Division for Public Institutions and Digital Government (DPIDG), previously known as the Division for Public Administration and Development Management (DPADM) [5]. The reports assess the status of e-government in different countries around the world, according to a specific set of measurements. Specifically, the assessment of egovernment in the UN reports is based on the following three major measurements $[4,5,25]$ :

- Online services index (OSI), also called web measurement index: This includes the measurement of four stages of online services, which are emerging presence (stage1), enhanced presence (stage2), transactional presence (stage3), and connected presence (stage4). 
- Telecommunications infrastructure index (TII): This includes the measurement of four indicators, which are the number of internet users per 100 people, the number of mobile cellular subscribers per 100 people, the number of active mobile broadband subscribers per 100 people, and the number of fixed broadband subscribers per 100 people.

- Human capital index (HCI): This includes the measurement of two indicators, which are adult literacy and the combined primary, secondary, and tertiary gross enrolment ratio.

Based on the above three measurements, the UN developed the e-government development index (EGDI), according to which each country is given a value indicating its world rank. The EGDI is a weighted average of the OSI, the TII, and the HCI. The EGDI can be mathematically presented as follows: $\mathrm{EGDI}=1 / 3((\mathrm{OSI})+(\mathrm{TII})+(\mathrm{HCI}))[4,5,25]$. Further information about the indicators of e-government can be found in Appendix A.

\section{RESEARCH METHODOLOGY}

The study made use of data collected from a number of sources, including e-government official reports, portals, and ICT statistics, all relating to the three countries considered in the study. However, the research focused primarily on the UN e-government survey reports, not only because these reports were considered thorough, rigorous, and comprehensive, but also because they were regarded as precise, and relevant to the study's research questions. The UN is considered a pioneering organization that assesses e-government on a global level.

For the purpose of the study, the comparison between the development of e-government in Saudi Arabia and in the USA and the RoK was made according to a specific set of numerical data taken from UN e-government reports ranging from 2003 to 2020.

It is important to consider data analysis as a critical part of any research methodology. It involves the process of using various methods in order to reveal specific results that address certain questions or objectives. In the case of this study, a number of data analysis techniques were used. These techniques are detailed as follows.

\section{A. Comparative, Cross-Country Analysis}

The study used comparative analysis to identify similarities and differences between Saudi Arabia, the USA, and the RoK, in relation to e-government development indicators, namely, EGDI, OSI, TII, and HCI. The timeframe of this analysis was the period 2003 to 2020.

\section{B. Trend Analysis}

Trend analysis was used to measure the development of egovernment in Saudi Arabia, the USA, and the RoK over the period 2003 to 2020 . Specifically, trend analysis in the present study was employed to determine the uptrend (positive slope) and the downtrend (negative slope) in relation to the egovernment indicators under consideration: EGDI, OSI and its sub-indicators (OSI1, OSI2, OSI3, OS4), TII and its subindicators (TII1, TII2, TII3, TII4), and HCI and its sub- indicators (HCI1, HCI2). In research methods literature, trend analysis is often referred to as a special data analysis technique of regression analysis. In this form of data analysis, the independent variable is time, whereas the dependent variable is the variable to be forecast [26]. In this study, the independent variable is represented by the period 2003 to 2020, while the dependent variables are represented by the above indicators.

\section{Gap analysis}

According to research methods literature, gap analysis can be used for various purposes. In the present study, it was used is to measure the gap between the development of egovernment in Saudi Arabia and the development of egovernment in the USA and the RoK, with reference to the indicators: EGDI, OSI and its sub-indicators (OSI1, OSI2, OSI3, OS4), TII and its sub-indicators (TII1, TII2, TII3, TII4), and $\mathrm{HCI}$ and its sub-indicators (HCI1, HCI2).

In terms of data analysis software, SPSS was used to conduct the trend analysis and to deal with missing data, by using the multiple imputation statistical method. MS Excel was also used to make the tables required for the comparative, cross-country analysis, the trend analysis, and the gap analysis, and to draw figures from these tables.

\section{Results}

\section{A. An Overview of the Development of e-Government in Saudi Arabia, the USA, and the RoK}

1) EGDI for Saudi Arabia, the USA, and the RoK: The EGDI values for each country considered in the study can be used to give an overview of the level of overall progress made in relation to the adoption and implementation of egovernment in these countries. Fig. 1 shows the EGDI values for Saudi Arabia, the USA, and the RoK during the period 2003 to 2020.

Fig. 1 indicates that, although the EGDI values for Saudi Arabia are still low, the country has made good progress in that these values have steadily increased over the years. Nonetheless, these values also indicate that Saudi Arabia needs to further improve e-government in the future. By contrast, in the case of e-government in the USA, the EGDI values were high, especially during the period 2003-2005. However, these values then dropped, particularly, in 2016. The EGDI values for the RoK began low during the period 2003-2010, then subsequently increased during the period 2012-2020.

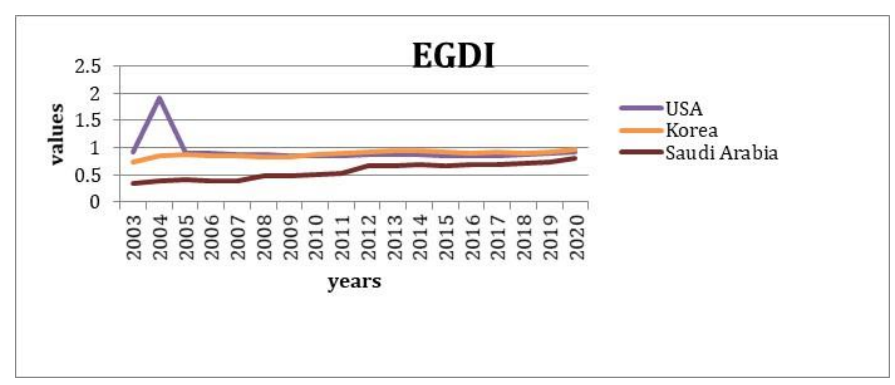

Fig. 1. EGDI Values for the USA, the RoK, and the KSA during the Period 2003 to $2020[3,4,25]$. 
As shown in Fig. 1, the EGDI values for Saudi Arabia have generally improved over the past 15 years. This improvement is particularly clear in 2010, 2012, 2014, 2016, 2018, and 2020. In a similar vein, the EGDI values for the USA have significantly improved over time. However, there was a notable drop in the EGDI for the USA in 2008, although it did begin to increase again in 2010. Fig. 1 also indicates a rapid improvement of the EGDI values for the RoK, particularly, over the period from 2012 to 2020.

2) Indicators of e-government for Saudi Arabia, USA, and RoK: The e-government indicators (OSI, TII, and HCI) for Saudi Arabia, the USA, and the Rok are based on the UN egovernment reports, shown in Appendix A. These indicators can be used to give a descriptive overview of the level of overall progress that has been made. Fig. 2 shows the values of OSI, TII, and HCI for the USA, the RoK, and Saudi Arabia during the period 2003 to 2020.

As can be seen from the values shown in Fig. 2, Saudi Arabia has made good progress in terms of all three indicators of the EGDI during the period 2003 to 2020. However, these values, if compared with those relating to the USA and the RoK, indicate that further development of e-government in Saudi Arabia is still required.

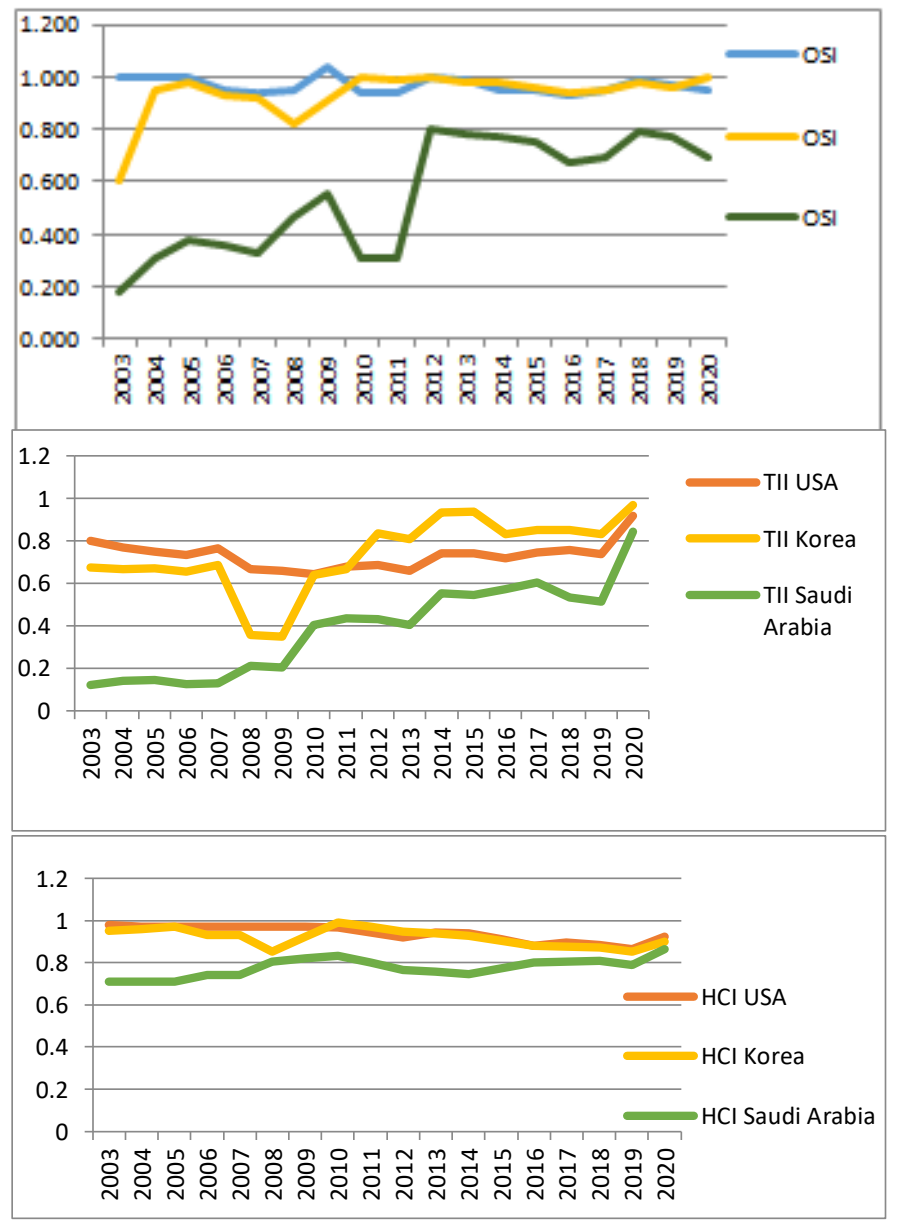

Fig. 2. OSI, TII \& HCI Values for the USA, the Rok, and the KSA during the Period 2003 to 2020 [3, 4, 25].
In terms of OSI, the Rok ranks highest with the value of 1, but the USA also has a high value, at 0.94. OSI for Saudi Arabia, on the other hand, has improved from only 0.18 in 2003, to 0.68 in 2020. Similarly, the TII values for both the USA and Saudi Arabia indicate an improvement, although the TII values for the RoK for the same period are better still. Nonetheless, it is worth noting that while the TII values for Saudi Arabia show constant improvement, the TII values for both the USA and the RoK show unsteady progress, most notably between 2008 and 2013 in the case of the USA, and between 2008 and 2011 in the case of the RoK.

The HCI values for Saudi Arabia indicate constant progress from 2003 to 2020 except during the period from 2012 to 2016, where these values dropped slightly. Similarly, HCI for both the USA and the RoK has higher values initially, especially from 2003 to 2014, but then decreases, particularly from 2016 to 2019 in the case of the USA, and from 2016 to 2020 in the case of the RoK.

Fig. 2 shows that Saudi Arabia has made steady progress in all indicators of e-government development during the period from 2014 to 2020 , although a drop was seen in the period from 2008 to 2012. Fig. 2 also indicates that, over time, HCI for Saudi Arabia has improved more than TII or OSI. This is also the case for both the USA and the RoK, where HCI values were higher than TII and OSI values.

\section{B. Trend Analysis Results}

Trend analysis was used to discover the uptrend (positive slope) as well as the downtrend (negative trend) in the UN egovernment indicators for the USA, the RoK, and Saudi Arabia. This form of data analysis is a distinct case of regression analysis in which time is considered the independent variable, whereas the variable to be forecasted is considered the dependent variable. In this study, dependent variables represent the EGDI and its indicators.

1) Trend analysis of EGDI: Table I shows the EGDI trend analysis for the USA, the RoK, and Saudi Arabia during the period 2003 to 2020.

As shown in Table I, the trend analysis of the EGDI values for Saudi Arabia indicates a steady improvement, with a positive trend value of 0.268 compared with a value of 0.0166 for the USA, and a value of 0.0077 for the RoK. This result highlights the fact that the EGDI for Saudi Arabia has generally improved over time, with the peak of its EGDI value in 2020 (0.7991). On the other hand, the trend analysis of the EGDI values for the USA points to a negative trend value, and the trend analysis of the EGDI for the RoK points to a positive trend value. This indicates that while the RoK has maintained high EGDI values over time, the EGDI values for the USA have dropped over time even though the USA had high EGDI values during earlier periods, especially during the period 2003 to 2005 .

2) Trend analysis of OSI and its sub-indicators: The trend analysis of the OSI values for the countries considered in this study can be used to infer the level of progress made in relation to online services and its sub-indicators, and whether the results of the trend analysis indicate a positive or a 
negative values. Table II shows the OSI trend analysis for Saudi Arabia, the USA, and the RoK during the period 2003 to 2020 .

The trend analysis of the OSI for Saudi Arabia indicates that online services have gradually improved, and this improvement has resulted in a positive trend value of 0.0388635 . In a similar vein, the trend analysis of the OSI for the RoK points to a positive value of 0.01042673 . On the other hand, the trend analysis of the OSI for the USA indicates a negative value of -0.0024602 . This is because the OSI values were lower during the period 2012 to 2020 than during the period 2003 to 2005, and in 2012 .

In terms of the OSI sub-indicators, Table II shows that Saudi Arabia has made good improvement with regards to the four online services stages that represent the OSI subindicators, with positive values of $1.35367647,1.93143382$, 6.49834559, and 2.93839614. In comparison with the OSI sub-indicators for the USA, Table II shows that stages 1, 2, and 4 have negative trend values of $-0.275,-0.7416131$, and 0.1834559 , respectively whereas only stage 3 has a positive trend value of 0.30857077 . This is because values of the OSI sub-indicators for the USA were higher during the period 2003 to 2008 than during the period 2016 to 2020 , where a decrease in these values can be particularly noted. On the other hand, the OSI sub-indicators for the RoK have positive trend values for three of the stages of online services, which are stage 1,3 , and 4 , with values of $0.005,1.28524816$, and 1.78713235 , respectively, and one negative trend value of .04082491 for stage 2 .

3) Trend analysis of TII and its sub-indicators: Table III shows the results of the trend analysis of TII and its subindicators for the USA, the RoK, and Saudi Arabia during the period 2003 to 2020.

TABLE I. TREND ANALYSIS RESULTS OF THE EGDI FOR THE USA, THE ROK, AND THE KSA DURING THE PERIOD 2003 TO 2020

\begin{tabular}{|l|l|}
\hline Country & Trend (Slope) of EGDI \\
\hline The USA & -0.0166 \\
\hline The RoK & 0.0077 \\
\hline The KSA & 0.0268 \\
\hline
\end{tabular}

TABLE II. TREND ANALYSIS RESULTS OF OSI AND ITS SUB-INDICATORS FOR THE USA, THE ROK AND THE KSA DURING THE PERIOD OF 2003 TO 2020

\begin{tabular}{|l|l|l|l|}
\hline \multirow{2}{*}{ Indicator } & \multicolumn{3}{|l|}{ Country } \\
\cline { 2 - 4 } & The USA & The RoK & The KSA \\
\hline OSI & -0.0024602 & 0.01042673 & 0.0388635 \\
\hline OSI1 & -0.275 & 0.005 & 1.35367647 \\
\hline OSI2 & -0.7416131 & -0.4082491 & 1.93143382 \\
\hline OSI3 & 0.30857077 & 1.28524816 & 6.49834559 \\
\hline OSI4 & -0.1834559 & 1.78713235 & 2.93839614 \\
\hline
\end{tabular}

TABLE III. TREND ANALYSIS RESULTS FOR TII AND ITS SUB-INDICATORS FOR THE USA, THE ROK AND THE KSA DURING THE PERIOD 2003-2020

\begin{tabular}{|l|l|l|l|}
\hline \multirow{2}{*}{ Indicator } & \multicolumn{3}{|l|}{ Country } \\
\cline { 2 - 4 } & The USA & The RoK & The KSA \\
\hline TII & 0.00372 & 0.01933 & 0.03858 \\
\hline TII1 & 2.12107 & 2.41639 & 5.00924 \\
\hline TII2 & 4.5183 & 3.75414 & 10.0155 \\
\hline TII3 & 3.11295 & 4.31919 & 4.90803 \\
\hline TII4 & 1.15821 & 1.012439011 & 1.19233 \\
\hline
\end{tabular}

TII for Saudi Arabia improved gradually, especially in 2020 when its value jumped to 0.8442 from only 0.211 in 2008. Thus, the results of the trend analysis of the TII values for Saudi Arabia during the period 2003 to 2020 show an annual improvement with a positive trend value of 0.03858 . In a similar vein, the results of the trend analysis of the TII values for both the USA and the RoK indicate positive values of 0.00372 for USA and 0.01933 for RoK. The following explains the results of the trend analysis of the TII subindicators.

The first sub-indicator of TII to consider here is the number of estimated internet users per 100 persons. The values of this indicator have been slowing improving over time. However, this indicator notably increased for Saudi Arabia in 2020. Similarly, it improved remarkably for the USA and the RoK in the same year (2020). The estimated number of internet users in Saudi Arabia increased to 87.27 in 2020, although it was just 18.66 in 2008. This has resulted in a positive trend value of 5.00924 for Saudi Arabia. Likewise, the estimated number of internet users in the USA as well as in the RoK increased in 2020, and this has resulted in positive trend values of 2.12107 , and 2.41639 for the USA and the RoK, respectively.

A second indicator to consider is the number of mobile subscribers. The number of mobile subscribers in Saudi Arabia was just about 78 in 2008, but this number gradually increased over time especially during the period 2012 to 2020 . This has resulted in a positive trend of 10.0155. Similarly, in the USA the estimated number of mobile subscribers was just about 74 in 2008, but this value increased remarkably, especially during the period 2014 to 2020 . This has resulted in a positive trend value of 4.5183 . On the other hand, the estimated number of mobile subscribers in the RoK was just about 83 in 2008, but this value increased greatly, especially during the period 2012 to 2020 . This has resulted in a positive trend value of 3.75413. E-government can be accessed and utilized via different devices, and the results of the trend analysis of this indicator points to great potential for egovernment, particularly with smart phones users.

In terms of active mobile broadband subscriptions, which is the third sub-indicator of TII, Table III shows that the USA, the RoK, and Saudi Arabia, all have positive trend values of $3.11395,4.31919$, and 4.90803 , respectively. The increasing number of mobile subscribers, which, in turn enables subscription to active mobile broadband, may be the reason why the trend values of this sub-indicator are also increasing. 
On the other hand, these countries have varied but positive trend values of $1.15821,1.012439011$, and 1.19233, respectively, in relation to fixed broadband subscription, which is the fourth sub-indicator of the TII. Nonetheless, the values of this indicator for Saudi Arabia during the period 2003 to 2020 are still lower than those of both the USA and the RoK, which indicates that this area needs further development.

4) Trend analysis of HCI and its sub-indicators: Table IV shows the results of the trend analysis of the HCI and its subindicators for the USA, the RoK, and Saudi Arabia during the period 2003 to 2020.

The HCI for Saudi Arabia, the USA, and the RoK generally improved during the period 2003 to 2020 . However, the HCI for Saudi Arabia decreased at times, especially during the period 2012 to 2016. As a result, as shown in Table IV, the HCI for Saudi Arabia has a negative trend value of 0.0020209 . Similarly, in 2008 the HCI for the RoK was 0.8056 , but this value then decreased, especially during the period 2012 to 2018, and this resulted in a negative trend value of -0.0114045 . Likewise, in 2008 the HCI for the USA was 0.9711 , but during the period 2010 to 2018 this value began to decrease, which resulted in a negative trend value of -0.00097055 .

In terms of the HCI sub-indicators, Table IV shows a positive trend value of 1.296 for Saudi Arabia in relation to HCI1, which represents adult literacy. On the other hand, Table IV shows a neutral value of 0 for both the USA, and the RoK in relation to HCI1, and this indicates maintenance of the same position over time. In contrast, Table IV shows a negative trend value of -0.2147455 for the RoK in relation to HCI2, which represents gross enrolment ratio, while positive trend values can be noted from Table IV in relation to HCI2 for both Saudi Arabia (2.20163636), and the USA (0.37845455).

\section{Gap Analysis Results}

Gap analysis is an approach for the steps to be taken to enable change from a present situation regarding an issue or a factor to a future, more desirable situation [26]. This can be achieved by studying, comparing, and understanding gaps between the examined factors or indicators. In the context of the current study, this form of analysis refers to an evaluation of the gaps between the e-government indicators for Saudi Arabia and those of the USA, and the gaps between the egovernment indicators for Saudi Arabia and those of the RoK. Because data that represent the three main indicators of egovernment exist in different forms, a per unit analysis was used to convert them to percentages to enable the proper comparison and to identify accordingly the priorities for indicators that require more attention.

1) Gap analysis of OSI indicators: Table V shows the results of the gap analysis between Saudi Arabia and the USA, and that between Saudi Arabia and the RoK in relation to indicators of their online services index.

In Table V, the indicators of the OSI are OSI1, OSI2, OSI3, and OSI4, which respectively represent: stage 1 (emerging presence), stage 2 (enhanced presence), stage 3 (transactional presence), and stage 4 (connected presence). Please see Appendix A for a description of these stages. The per unit analysis values for these four indicators were calculated according to the following formulas:

- P_OSI1= ((OSI1-Min value)/(Max value -Min value $))$ * 100

- P_OSI2= ((OSI2-Min value $) /($ Max value - Min value $))$ * 100

- P_OSI3= $(($ OSI3-Min value $) /($ Max value - Min value $))$ $* 100$

- P_OSI4= ((OSI4-Min value)/(Max value -Min value $))$ $* 100$

Gap analysis values, on the other hand, were calculated according to the following formulas:

- The USA P_OSI1 - the KSA P_OSI1

- The USA P_OSI2 - the KSA P_OSI2

- The USA P_OSI3 - the KSA P_OSI3

- The USA P_OSI4 - the KSA P_OSI4

- The Rok P_OSI1 - the KSA P_OSI1

- The Rok P_OSI2 - the KSA P_OSI2

- The Rok P_OSI3 - the KSA P_OSI3

- The Rok P_OSI4 - the KSA P_OSI4

According to Table $\mathrm{V}$, there is a significant gap in relation to all four sub-indicators of the OSI between the values of Saudi Arabia and the values of both the USA and the RoK, which were equivalent. The results of the gap analysis shown in Table V indicate that the gap between the values of Saudi Arabia and those of the USA and the RoK are 26.93\%, $19.05 \%, 28.58 \%$, and $54.55 \%$ in relation to OSI 1 , OSI2, OSI3, and OSI4, respectively. Notably, this gap is greater for OSI4 than for the other three sub-indicators of the OSI. This indicates that Saudi Arabia needs to further invest in developing its online services at different levels to address the current gap.

2) Gap analysis of TII indicators: Table VI shows the results of the gap analysis between Saudi Arabia and the USA, and that between Saudi Arabia and the RoK in relation to the indicators of their TII.

TABLE IV. TREND ANALYSIS RESULTS OF HCI AND ITS SUB-INDICATORS FOR THE USA, THE ROK AND THE KSA DURING THE PERIOD 2003-2020

\begin{tabular}{|c|c|c|c|}
\hline \multirow{2}{*}{ Indicator } & \multicolumn{3}{|l|}{ Country } \\
\hline & The USA & The RoK & The KSA \\
\hline $\mathrm{HCI}$ & -0.0097055 & -0.0114045 & -0.0020209 \\
\hline HCI1 & 0 & 0 & 1.296 \\
\hline $\mathrm{HCI} 2$ & 0.37845455 & -0.2147455 & 2.20163636 \\
\hline
\end{tabular}


TABLE V. OSI INDICATORS PER UNIT AND GAP ANALYSIS

\begin{tabular}{|c|c|c|c|c|}
\hline Country & OSI1 & OSI2 & OSI3 & OSI4 \\
\hline The USA & 100 & 100 & 100 & 100 \\
\hline The RoK & 100 & 100 & 100 & 100 \\
\hline The KSA & 74.07 & 80.95 & 72.09 & 45.45 \\
\hline Max value & 100 & 100 & 100 & 100 \\
\hline Min value & 3.70 & 0 & 2.33 & 0 \\
\hline Per Unit Analysis & P_OSI1 & P_OSI2 & P_OSI3 & P_OSI4 \\
\hline The USA & 100 & 100 & 100 & 100 \\
\hline The RoK & 100 & 100 & 100 & 100 \\
\hline The KSA & 73.07 & 80.95 & 71.42 & 45.45 \\
\hline Gap Analysis & Gap_P_OSI1 & Gap_P_OSI2 & Gap_P_OSI3 & Gap_P_OSI4 \\
\hline Between the KSA and the USA & 26.93 & 19.05 & 28.58 & 54.55 \\
\hline Between the KSA and the RoK & 26.93 & 19.05 & 28.58 & 54.55 \\
\hline
\end{tabular}

TABLE VI. TII INDICATORS PER UNIT AND GAP ANALysis

\begin{tabular}{|l|l|l|l|l|}
\hline Country & TII1 & TII2 & TII3 & 120 \\
\hline The USA & 93.3 & 120 & 120 & 113.63 \\
\hline The RoK & 96.02 & 120 & 111.09 & 33.8 \\
\hline The KSA & 87.27 & 120 & 120 & 41.6 \\
\hline Max value & 99.01 & 20.74 & 0 & 20.24 \\
\hline Min value & 0 & P_TII2 & P_TII3 & 51.24 \\
\hline Per Unit Analysis & P_TII1 & 99.105 & 100 & 0 \\
\hline The USA & 94.23 & 99.105 & 94.69 & P_TII4 \\
\hline The RoK & 96.98 & 99.105 & 92.57 & 65.96 \\
\hline The KSA & 87.86 & Gap_P_TII2 & Gap_P_TII3 & 7.18 \\
\hline Gap Analysis & Gap_P_TII1 & 0 & 7.43 & Gap_P_TII4 \\
\hline Between the KSA and the USA & 6.37 & 0 & 2.12 & 26.46 \\
\hline Between the KSA and the RoK & 9.12 & & 41.68 \\
\hline
\end{tabular}

In Table VI, the column headers TII1, TII2, TII3, and TII4, respectively represent the sub-indicators of the TII: the number of internet users per 100 persons; the number of mobile cellular subscribers per 100 persons; the number of active mobile broadband subscribers per 100 persons; and the number of fixed broadband subscribers per 100 persons. The per unit analysis values of these indicators for each country were calculated according to the following formulas:

- P_TII1 $=(($ TII1-Min value $) /($ Max value - Min value $))$ $* 100$

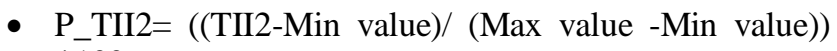
$* 100$

- P_TII3= $(($ TII3-Min value $) /($ Max value - Min value $))$ $* 100$

- P_TII4= ((TII4-Min value $) /($ Max value - Min value $))$ $* 100$
The gap analysis values of these four indicators, on the other hand, were calculated according to the following formulas:

- The USA P_TII1 - the KSA P_TII1

- The USA P_TII2 - the KSA P_TII2

- The USA P_TII3 - the KSA P_TII3

- The USA P_TII4 - the KSA P_TII4

- The Rok P_TII1 - the KSA P_TII1

- The Rok P_TII2 - the KSA P_TII2

- The Rok P_TII3 - the KSA P_TII3

- The Rok P_TII4 - the KSA P_TII4

According to Table VI, there is a significant gap between Saudi Arabia and both the USA and the RoK in relation to two sub-indicators of the TII, which are TII3, and TII4. The results of gap analysis that are shown in Table VI indicate that, in 
terms of TII3, there is a gap between Saudi Arabia and the USA by $7.43 \%$, and by $19.05 \%$ between Saudi Arabia and the RoK, whereas, in terms of TII4, the gap is even greater between Saudi Arabia and the USA (26.46\%) and between Saudi Arabia and the RoK $(41.68 \%)$. This indicates that Saudi Arabia needs to further develop its national telecommunication infrastructure, especially in relation to TII 3 and TII4, to address this current gap.

On the other hand, there is a moderate gap between Saudi Arabia and the USA of $6.37 \%$, and between Saudi Arabia and the RoK of $9.12 \%$ with regards to TII1. Notably, there is no gap between Saudi Arabia and either the USA or the RoK in relation to TII2, which indicates improvement and progress for Saudi Arabia.

3) Gap analysis of HCI indicators: Table VII shows the results of the gap analysis between Saudi Arabia and the USA, and that between Saudi Arabia and the RoK in relation to indicators of their HCI.

In Table VII, HCI1 and $\mathrm{HCI} 2$ respectively represent indicators of the HCI which are Adult Lteracy (AL) and Gross Enrolment Ratio (GER). The per unit analysis values for these two indicators for each country were calculated according to the following formulas:

- $\quad$ P_HCI1= $(($ HCI1-Min value $) /($ Max value - Min value $))$ * 100

- $\quad$ P_HCI2= ((HCI2-Min value $) /($ Max value - Min value $))$ $* 100$

- $\quad$ __HCI3 $=(($ HCI3-Min value $) /($ Max value - Min value $))$ $* 100$

- $\quad$ P_HCI4= ((HCI4-Min value $)$ / (Max value -Min value $))$ $* 100$

The gap analysis values of these two indicators, moreover, were calculated according to the following formulas:

- The USA P_HCI1 - the KSA P_HCI1

- The USA P_HCI2 - the KSA P_HCI2

- The USA P_HCI3 - the KSA P_HCI3

- The USA P_HCI4 - the KSA P_HCI4

- The Rok P_HCI1 - the KSA P_HCI1

- The Rok P_HCI2 - the KSA P_HCI2

- The Rok P_HCI3 - the KSA P_HCI3

- The Rok P_HCI4 - the KSA P_HCI4

According to Table VII, there is a moderate gap of $4.54 \%$ between Saudi Arabia and both the USA and the RoK in relation to HCI1. This indicates that further effort is required to address the gap. On the other hand, the HCI2 values for Saudi Arabia are even higher than the HCI2 values for the USA and the RoK, which indicates significant improvement and progress for Saudi Arabia.
TABLE VII. HCI INDICATORS PER UNIT AND GAP ANALYSIS

\begin{tabular}{|l|l|l|}
\hline Country & HCI1 & HCI2 \\
\hline The USA & 95.33 & 100 \\
\hline The RoK & 99 & 98.38 \\
\hline The KSA & 99 & 97.48 \\
\hline Max value & 100 & 115.41 \\
\hline Min value & 19.1 & 17 \\
\hline Per Unit analysis & P_OSI1 & P_OSI2 \\
\hline The USA & 94.22 & 84.34 \\
\hline The RoK & 98.76 & 82.69 \\
\hline The KSA & 98.76 & 81.78 \\
\hline Gap analysis & Gap_P_OSI1 & Gap_P_OSI2 \\
\hline Between the KSA and the USA & 4.54 & -1.65 \\
\hline Between the KSA and the RoK & 4.54 & -2.56 \\
\hline
\end{tabular}

\section{DISCUSSION}

While e-government is well-instituted in developed countries, this is not usually the case in developing countries due to the various challenges these countries face in terms of e-government adoption and implementation [12]. These challenges, whether technical, organizational, or legal, contribute to the overall e-readiness index values, which are published in UN e-government reports, of these countries. Thus, for each developing country, it is vital to identify, and accordingly to address each of these challenges. Saudi Arabia is one of these developing countries, and it also encounters technical, organizational, and legal challenges [1,14,23] that, if adequately addressed, could boost the country's rank and its EGDI index, which are shown in the 2020 UN e-government report. The results of the current study reveal that the values of the EGDI and its components for Saudi Arabia have steadily increased in recent years. However, the results also indicate that there are different areas that need further attention and, consequently, additional improvement. An information management strategy (IMS) in support of e-government in Saudi Arabia is therefore proposed and is shown in Fig. 3 below.

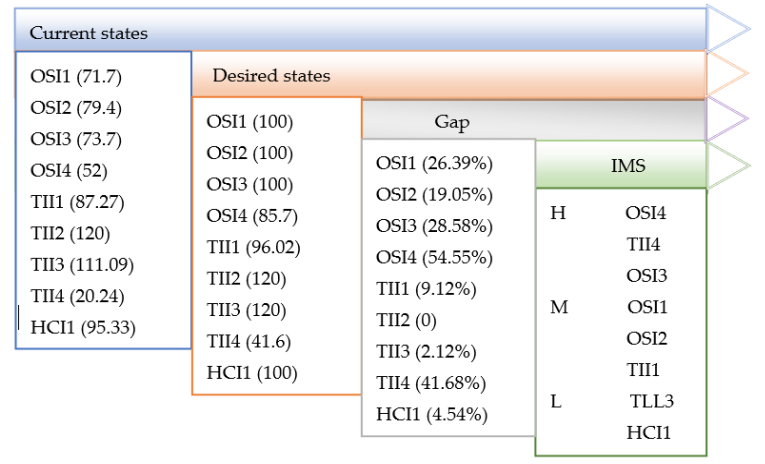

Fig. 3. Information Management Strategy for e-government in Saudi Arabia. 
The strategy shown in Fig. 3 describes the current and desired states of e-government in Saudi Arabia in relation to egovernment indicators that have been analyzed in the current study. The values for the current state represent the results of the trend analysis of the OSI, TII, and HCI indicators for Saudi Arabia, whereas the values of the desired state represents the results of the trend analysis of the OSI, TII, and $\mathrm{HCI}$ indicators for the RoK, as these were the highest values of the three countries considered in this study. Furthermore, the values in the third column represent the gaps percentages based on the gap analysis that was conducted in the current study between Saudi Arabia and the RoK in relation to the OSI, TII, and HCI indicators.

The information management strategy shown in Fig. 3 also sets three levels of priorities for areas that Saudi Arabia needs to consider to better comply with international e-government practices. The highest priorities include OSI4, TII4, and OSI3. Saudi Arabia needs to further develop its online services, particularly its connected and interactive services, its Internet fixed-broadband infrastructure, and its transactional online services. Furthermore, the medium-level priorities include the need to re-consider increasing the presence of additional and more developed online services and increasing the number of internet users all over the country. E-government online services for all citizens, including those with special needs, requires more attention. Finally, Fig. 3 sets low priorities for e-government in Saudi Arabia, which include further development of active mobile broadband subscriptions and further investment in human capital. It is important to reconsider the development of the HCI in Saudi Arabia, as this factor may have an impact on other e-government indicators, namely, the OSI and TII. Indeed, a recent study by [14] (p. 10) suggested that "whenever the good HCI exist, the growth of OSI and TII will increase" and "when there is no good HCI, the growth of OSI and TII will decrease".

The significance of the proposed strategy in this study is that it depicts the main factors that the Saudi government needs to account for during the continued process of developing and implementing e-government. Specifically, this study argues that technical factors, especially those relating to online services and infrastructure issues, need to be first reconsidered to achieve successful implementation of egovernment and to consequently improve the current state of country's EGDI. This is in line with a recent study [14] that found that infrastructure was the key challenge impacting the successful implementation of e-government in the Arab world.

\section{CONCLUSION}

The aim of the current study was to benchmark the level of progress of the e-government in Saudi Arabia with two global e-government leaders: the USA and the RoK. This researcher conducted: a) a comparative, cross-country, longitudinal analysis of the e-government development index (EGDI) values that relate to Saudi Arabia, the USA and the RoK, b) a trend analysis of the online services, telecommunication infrastructure, and human capital indicators, and c) a gap analysis to pinpoint the gap between Saudi Arabia and the USA and the gap between Saudi Arabia and the RoK. The results reveal a continuous and steady rise in the rankings of the Saudi EGDI over the years. However, the results also indicate that some areas require more improvement. An information management strategy for the support of egovernment in Saudi Arabia is therefore proposed.

Given the current situation of the Coronavirus pandemic, the role of digital transformation and e-government in both developed and developing countries is considered highly significant. Academic research that comparatively evaluates the development of e-government longitudinally is still limited. This research paper is significant in that it extends the existing literature on the development of e-government by adopting a cross-country, longitudinal analysis, based on EGDI indicators of UN e-government reports during the period 2003-2020, to assess the overall progress of egovernment in three countries: Saudi Arabia, the USA, and the RoK. It should be noted that the results of this study are based on specific data analysis techniques, and thus interpretations of these results should be considered in the context of such techniques. Nonetheless, the current study is significant in that it is one of the few studies that not only evaluates and compares the evolution of e-government in Saudi Arabia with that of the USA and the RoK, but also presents an information management strategy that prioritizes a number of areas that need to be considered to further develop e-government in Saudi Arabia.

The findings of the current study can be used by policymakers and IT managers in Saudi Arabia not only to focus on areas that need further consideration and development, but also to monitor and evaluate each step made that would enable the full realization of the benefits of egovernment. The model proposed in the study can be thus used by e-government policymakers to consider the main factors that need to be taken into account during the continual process of developing and implementing e-government.

\section{REFERENCES}

[1] Gharibi, W.; Khan, M.A. E-government in the Arab world: Analysis and perspective. In Proceedings of the 2014 World Congress on Computer Applications and Information Systems (WCCAIS), Hammamet, Tunisia: Curran Associates, Inc.: New York, USA. 2014.

[2] Ndou, V. E - government for developing countries: opportunities and challenges. The Electronic Journal on Information Systems in Developing Countries, Vol 18, 1-24, 2004.

[3] Fidel et. al The Case for e-government: Excerpts from the OECD Report: the e-government Imperative. OECD Journal on Budgeting, Vol 3, pp. 61-96, 2003.

[4] United nations department for economic and social affairs. United nations E-government survey 2018; United nations: New York, 2019.

[5] United nations department for economic and social affairs. United nations E-government survey 2020; ; United nations: New York, 2020.

[6] Alshehri, M.; Drew, S. Challenges of e-government Service Adoption in Saudi Arabia from e-Ready Citizen Perspective. IADIS International Conference ICT, Society and Human Beings, Freiburg, Germany: IADIS Press, Lisbon, Portugal, 2010.

[7] Benedetti, M.; Ghezzi, C.; Russo, C.; Lamberti, L. Towards a user-centric e-government service design: evidences from Italy. In A.R. Shark e Toporkoff, S. (eds.) Beyond e-Government Measuring Performance: A global perspective: BookSurge Publishing, 2009.

[8] Lamberti, L.; Benedetti, M.; Chen, S. Benefits sought by citizens and channel attitudes for multichannel payment services: Evidence from Italy. Government Information Quarterly, Vol 31, pp. 596-609, 2014. 
[9] Detlor, B.; Hupfer, M.E.; Ruhi, U.; Zhao, L. Information quality and community municipal portal use. Government Information Quarterly, Vol 30, pp. 23-32, 2013.

[10] Arendsen, R.; Peters, O.; ter Hedde, M.; van Dijk, J. Does e-government reduce the administrative burden of businesses? An assessment of business-to-government systems usage in the Netherlands. Government Information Quarterly, Vol 31, pp. 160-169, 2014.

[11] Mundy, D.; Musa, B. Towards a Framework for eGovernment Development in Nigeria. Electronic Journal of e-government, Vol 8, pp. 148-166, 2010.

[12] Twizeyimana, J.D.; Andersson, A. The public value of E-Government A literature review. Government Information Quarterly, Vol 36, pp. 167$178,2019$.

[13] Heeks, R. Most eGovernment-for-Development Projects Fail: How Can Risks be Reduced? iGovernment working paper number 14, Manchester: The University of Manchester, 2003.

[14] Qasem, M.H.; Elkadi, H.K.; Ghoneim, S.G. E-Government in Arab Countries: challenges and Evaluation. Journal of Computer Engineering, Vol 20, pp. 1-11, 2018.

[15] Lau, E.M. 5 Th Global Forum on Reinventing Government Mexico City, 5 November 2003 Challenges for E-government Development Oecd Egovernment Project Organisation for Economic Co-operation and Development, 2003.

[16] Al-Busadiy, M.; Weerakkody, V. E-government services in Oman: An employee's perspective. Electronic Government (EG), Vol 8, pp. 185207, 2011.
[17] General Authority for Statistics in Saudi Arabia offical website. Available online: https://www.stats.gov.sa/en (accessed on 1st Oct 2020).

[18] Almufarrij, T. The Kingdom's annual population growth rate. Saudi Gazette Newspaper report, April 2, 2018.

[19] The Ministry of Communication and Information Technology in Saudi Arabia. Digital government strategy 2012. Available online: https://www.yesser.gov.sa/en/for-government/digital-governmentstrategy-2012 (accessed on 2nd Oct 2020).

[20] The Ministry of Communication and Information Technology in Saudi Arabia. E-government Program (Yesser). Available online: https://www.my.gov.sa/wps/portal/snp/pages/agencies/agencyDetails/AC 319 (accessed on 1st Oct 2020).

[21] The Ministry of Communication and Information Technology in Saudi Arabia offical website. Available online: https://www.mcit.gov.sa/en/page/175492 (accessed on 2nd Oct 2020).

[22] Omari, A. Technology Adoption in the Arabian Gulf Countries: The Case of E-Government. IJCSEIT, Vol 3, pp. 1-8, 2013.

[23] Alghaith, W.; Sanzogni, L.; Sandhu, K. Factors Influencing the Adoption and Usage of Online Services in Saudi Arabia. EJISDC, Vol 40, pp. 1-32, 2010.

[24] Borras, J. International Technical Standards for E-Government. Electronic Journal of E-Government, Vol 2, pp. 75-80, 2004.

[25] United nations department for economic and social affairs. United nations E-government survey 2016; United nations: New York, 2016.

[26] Alshomrani, S. A Comparative Study on United Nations E-Government Indicators between Saudi Arabia and USA. Journal of Emerging Trends in Computing and Information Sciences, Vol 3, pp. 411-420, 2012.

APPENDIX A: E-GOVERNMENT INDICATORS AS DEFINED IN THE UN E-GOVERNMENT REPORTS OF 2016 AND 2020

- Online services index (OSI): A main indicator of the EGDI that evaluates the scope, nature, and quality of online e-government services.

- OSI1: stage1: Provision of basic e-government services.

- OSI2: stage2: Provision of greater information resources and services.

- OSI3: stage3: Provision of a two-way services approach between citizens and government agencies.

- OSI4: stage4: Advanced e-government services that connect government to government, government to citizens, and citizens to government.

- Telecommunication infrastructure index (TII): A main indicator of the EGDI that evaluates the status and quality of the telecommunication infrastructures for enabling the provision and delivery of online e-government services.

- Human capital index (HCI): A main indicator of the EGDI that evaluates the status and levels of human capital that relate to a particular country. 